\title{
ANESTHETIC CONSIDERATION IN CARDIAC PATIENTS UNDERGOING NONCARDIAC SURGERY
}

\author{
Husham Mohamed Abdallah Zakaria \\ Universitatea de Medicina și Farmacie "Carol Davilla”, Str. Dionisie Lupu nr. 37 \\ Bucharest, Romania; Alshaab Teaching Hospital, Khartoum, Sudan \\ e-mail: hishca@gmail.com
}

\begin{abstract}
One ofthe biggest challenge today is the safe conduct of anesthesia for patients who might be elderly, have preexisting cardiac diseases and are secheduled to undergo noncardiac suergery. Within financial conestraints of today health services. The aproppriate investigations need to be decided and performed for these patients, in order to inform the anesthetist,surgeon and the patient of the risk of surgery. These should be undertaken only if they will influence management of the patient. The preoperative assessment will help with the formation of a perioperative management plan. Including preoperative optimization and postoperative care, inorder to minimize the risk of an adverse autcome.The most recent guidelines for preoperative evaluation for noncardiac surgery are discussed in details, including assessment of risk factors, andcardiac investigation. Current thinking in preoperative therapy, intraoperative management and postoperative management is discussed, although most patients with cardiac disease have ischaemic heart disease, other specific cardiac conditions and the principles of their management are discussed.
\end{abstract}

Administration of anaesthesia to patients with preexisting cardiac diseases is one of interresting challenge. Most common cause of perioperative morbidity and mortality in cardiac patients is ischaemic heart diseases (IHD). IHD is number one cause of morbidity and mortality all over the world. Approximately 7 million are considered to be at high risk of IHD.

Goldman et al. reported that 500,000 to 900,000 myocardil infarction occurs annually worldwide with subsequent mortality and mortal other cardiacity of $10-25 \%$. Care of this patients require identification of risk factors, preoperative evaluation and optimization, medical therapy, monitoring and the choice of appropriate anesthetic technique and drugs.

Risk factors -influencing perioperative cardiac mortality are: recent myocardial infarction; congestive heart failure; peripheral vascular diseases; angina pectoris; diabetes mellitus; hypercholesterolemia; dysrhythmias; age; renal dysfunction, obesity; life style and smoking.

Risk factors stratification.

In 1977 Goldman landmark cardiac risk index which was used extesively for preoprative risk assessment for the next tow decades.

Other cardiac risk indices where proposed and adopted. In 1996 a12-member task force of the American College of Cardiology and American
Heart Association (ACC/AHA) published guidelines regarding the preoperative cardiovascuar evaluation of patients undergoing noncardiac surgery.

In 2002 these guidlines were updated based on new data:

Evaluation:

Patient having any sort of cardiac ailment need to be evaluated properly preoperatively.

History:

Elicits the severity, progression and functional limitation introduced by cardiac disease. History should include:

1. Exercise tolerance it depicts reserve, it can be exellent. History of participating in sports. Adequate patient able to climb stairs, run a short distance. Poor patient able to do leisure activities only e.g slow ballroom dancing or can walk around in the house only.

2. Angina pectoris: it is symptomatic manifestation of myocardial ischaemia characterized by typical substernal pain which is provoced by physical exertion and relieved by rest or sublingual nitroglycerine.

3. Myocardial infarction: the incidence of MI during the perioperative period is related to time period since the previous MI 
4. Co-existing noncardiac diseases: a-peripheral vascular diseases b-cerebrovascular diseases c-chronic obstructive diseases d-renal dysfunction e-diabetes mellitus f-anaemia, polycythemia, thrombocytosis

5. Current medication, awareness about the medication that patient is taking is important during anaesthesia. All medication like Beta blockers calcium channel blockers, nitrates should be continued untill the morning of surgery.

6. Congestive cardiac failure.

7. Dysrhythmias.

\section{Examination:}

A carefull general physical examination should be done. It's include assessment of vital signs like blood pressure, pulse rate, rhythm, jugular venous pulse, oedema, pallor, cyanosis, clubbing, jaundice, lymphadenopathy.

In systemic examination, cardiovascular system should be examined for heart sounds, any murmurs. Respiratory system also needs to be assessed in details.

Laboratory investigations:

Cardiac specific tests like ECG, Echocardiograhy, to know ejection fraction, any valvular lesions, wall motion abnormalities, LV function and pressure gradients. Holler monitoring, treadmill test, thallium scintigraphy to detect myocardium of risk, radionuclide ventricuography, dobutamine stress test (DST) for evaluating inducible ischemia in patients who have poor functional capacity. Coronary angiography in patients where DST is positive should be done.

Anesthetic management:

anesthesia goals remain

1-sable hemodynamics

2-prevent MI by optimizing myocardial oxygen supply and reducing oxygen demand

3-monitor for ischemia

4-treat ischemia or infarction if it develop

5-normothermia

6-avoidance of significant anaemia

Management depends upon the type of surgery whether emergency or elective. For emergency surgery proceed for the surgery with medical management of cardiac ailment. For elective surgery perioperative management depends upon, clinical risk factors and surgery specific risk factors.

Clinical risk factors:

Obtained by history, physical examination review echocardiograhy, risk factors are grouped into 3 categories:

1- major clinical predictors: -unstable coronary syndrome -decompensated heart failure -significant dysrrhythias

andsevere valvular diseases

2-Intermediate clinical predictors: -mild angina pectoris, previous MI by history or pathological Q waves, compensated or prior heart failure, insulin dependent diabetes mellitus and renal insufficiency

3-minor clinical predictors:

-hypertension, left bundle branch

block, nonspecific ST-T waves changes and history of stroke

Surgery specific risk:

1-High risk surgery: emergent major operation particularly in the elderly, aortic and other major vascular surgery. Anticipated prlong surgical procedures associated with large fluid shift or anticipated blood loss. Cardiac risk is $>$ $5 \%$.

2-intermediate risk factors:carotid endarterectomy, head and neck surgery, prostate surgery, intraperitoneal and itrathoracic surgery, cardiac risk is $<5 \%$.

3-Low risk procedures: endoscopic procedures, suerficial procedures, catarat surgeries, breast surgeries, cardiac risk is $<1 \%$.

Preoperative management:

At risk patients need to be managed with pharmacological and other perioperative interventions that can ameliorate perioperative cardiac events

1-Optimisation of medical management.

2-Revascualarization by PCI, revascularizationby surgery by ( $\mathrm{CABG}$ ).

B-blockers have been shown to be useful in reducing periopertive morbidity and mortality in high risk patients and preferably titrated to a heart rate of 50-60 bpm. Alfa 2 agonists can be useful in patients where Beta blockers are contraindicated. Nitroglycerine lowers LVEDP by reducing preload, it improves collateral coronary flow and reduce systemic blood pressure. 
Coronary intervention should be guided by patients cardiac condition and by potential consequences of delaying noncardiac surgery for recovery after coronary revascularization.

Preanesthetic considerations:

-Preoperative visit is very important

-Concent obtaining

-Explanation about risk factors

-Continue the medication till the day of surgery. Beta blockers, Calcium channel blockers, Digitalis, Potassium level shoud be normal as hypokalemia can cause digitalis toxicity. Anticoagulants should be stopped.

Premedication:

-To reduce anxiety, to prevent increase in blood pressure and toheart rate, which can disturb the myocardial oxygen supplyand demand and can jnduce ischemia.

Combination of Benzodiazebine and opioids should be given one hour prior to arrival in operating room (Figure 1).

Intraoperative management:

Monitoring:

-ECG should be set on diagnostic mode, monitoring 3 leads improve recognition of ischemia.

-Blood pressure, pulse oximetry, capnography, temperature monitoring, urine output monitoring, control of venous pressure and cardiac output, TEE.

Choice of anesthesia:

Drugs should be selected with the objective of minimizing demand and optimum supply of oxygen and some cardiac drugs shoud be available to maintain hemodynamics to prevent and treat ischemia if it occurs.

General anesthesia

1 -intravenous anesthetics

-Thiopental decreases myocardial contractility, preload and blood pressure with slight increase of heart rate, it should be administered slowly.

-Propofol decreases blood pressure and heart rate significantly there is adose dependent reduction in myocardial contractility

-Ketamine is not good with IHD and valvular diseases

-Midazolam decreases mean arterial pressure and increases heart rate, provide exellent amnesia.

-Etomidate causese minimum hehodynamic changes. Excellent for induction in patients with poor cardiac reserve.
Narcotics: morphine is the preferred drug for its relative cardiac stability and very good analgesic effect

-Inhalational agents: isoflurane for patients with good myocardial contractility. Halothane has disadvantage of myocardial depression and potential of dysrhythmias.

-Nitrous oxide provides stabe hemodynamic

-Muscle relaxants vecuronium produces minimum hemodynamic alteration and is a short acting pipecuronium, mivacuriumand dexacurium without any significat cardiovascular side effect.
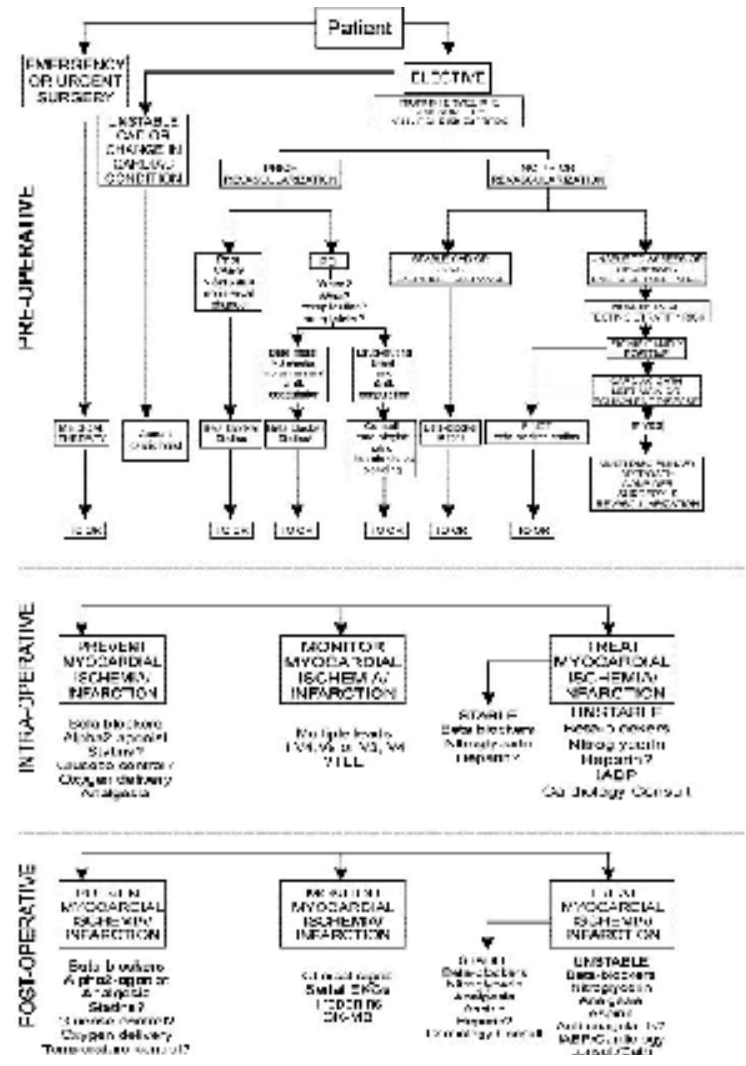

Figure 1 - Scheme of evaluation of the patient

-Glycopyrrolate is preferred over atropine, it producses less tachycardia.

-Regional anesthesia. The potential and well known advantage of RA over GA should be asset in cardiac patients if surgery can performed under RA disavatge of RA include hypotention, care should be taken while giving local anesthetics Managing intraoperative complications: 
1-Ischemia if patient hemodyamically stable Beta blockers and nitroglycerine. Heparin after consultation winth surgeon.

If patient hemodynamicaly unstable support with inotropes.use of intraoperative ballon pump may be necessary urgent consultation with cardiologist to plan for earliest possible catheterization other complication like dysrhythmias, paemaker dysfunction should managed accordingly.

Postoperative management:

Goals:

-Prevent ischemia, monitor for myocardial infarction, treatment for myocardial infarction.

-Although most cardiac events occurs within first 48 hours delayed cardiac event (with 30 days) still happen, and could be the of secondary stress, postoperative stress of extubation, pain, sepsis, hemorrage, anemia,, respiratory problemes can increase demand on the heart and should be minimized and treated.

Valvular heart diseases:

Patients with valavular heart diseases coming for surgery present many challenges .Now it is no longer necessary or even advisable to delay surgery until advanced symptoms are present. The five variables in dealing with the valvular heart diseases are important I-preload II-afterload IIImyocardial contractility IV-heart rate V-rhythym.

Hypertension:

Is the commonest cardiac disease all over the world.these patients are decumented to have associted CAD left ventricula dysfunction, renal failure which incease the perioperative risk it is important to control BP preoperatively.But this does not need surgery to be deferred for weeks, to achieve ideal blood pressure control, inpatients with mild to moderate hypertension.it is important to evaluate for target organ damage .it is advisable to continue antihypertensives till day of surgery any factors of sympathetic stimulus should be avoided.

Dysrhythmias:

May be a marker of severity of underlying CADor left ventricular dysfunction.A symptomatic ventricuka ectopics with stable hemodynamic parameters does not need any treatment preoperatively.prophylactic treatment is not required in supraventricular tachycardia. In a trial fibrillation rate needs to be controlled perioperatively if they occur can be treated by calcium channel blockers beta blockers adenosine.

Patients with conduction delay LBBB do not require pacing unless there is a history of syncope. But in complete heart block patients need to be paced. In patients with pace makers, electro cautary should be used with caution and for minimum period of time. The cautary plate should be as far as possible from the heart. Use of bipolar cautary decreases the risk of pacemaker dysfunction.

\section{References}

[1] Barash B.G., Sequential monitoring of myocardial ischemia in the perioperative period. In: American Society of Anaesthesiology, 2005, p. 411.

[2] Detsky A.S., Abrams H.B., Forbath N. et al., Cardiac assessment for patients undergoing noncardiac surgery. A multifactorial clinical risk index. Arch intem Med 1986, 146:2131

[3] Dupius J.Y., Labinaz M., Noncardiac surgery in patients with coronary artery stent : what should the anesthesiologist know, Can J Anesth 2005:52:356

[4] Eagle K. A., Brundage B., Chaitman B. et al., Guidelines for perioperative cardiovascular evaluation for non-cardiac surgery. AHA/ACC task force report. J Am Coll Cardiol 1996, 27:910 [5] Eagle K. A., Berger P.B., Calkins H. et al., ACC/AHA guidelines update for perioperative cardiovascular evaluation for noncardiac surgeryexecutive summary. A report of American College of Cardiologist/American Heart Association Task force on Practice Guidelines (Committee to update the 1996 guidelines on Preoperative Cardiovascular Evaluation for Noncardiac Surrey).Anesth Analg 2002; 94:1052

[6] Goldman L., Caldera D., Nussbaum S. et al., Mulyifactorial index of cardiac risk in noncardiac surgical procedures.N Engl JmED 1977:297:845

[7] Hall M. J., Owings M.F., Advance Datafrom vital and health statistics No:329, National Hospital Discharge survey. Hyattsville MD:Department of health and human Services; 2002, No:329 